\title{
The kinetics of gasification of char derived from sewage sludge
}

\author{
Lech Nowicki · Anna Antecka · Tomasz Bedyk • \\ Paweł Stolarek $\cdot$ Stanisław Ledakowicz
}

Received: 23 June 2010/Accepted: 31 August 2010/Published online: 18 September 2010

(C) The Author(s) 2010. This article is published with open access at Springerlink.com

\begin{abstract}
Gasification of char derived from sewage sludge was studied under different oxidizing atmospheres containing $\mathrm{CO}_{2}, \mathrm{O}_{2}$ or $\mathrm{H}_{2} \mathrm{O}$. The gasification tests were carried out in thermobalance at different temperatures and oxidizing reagent concentrations. The most efficient were the gaseous mixtures containing oxygen. The reaction took place at temperature $400-500{ }^{\circ} \mathrm{C}$, whilst in the case of $\mathrm{CO}_{2}$ and steam much higher temperatures $\left(700-900{ }^{\circ} \mathrm{C}\right)$ were necessary to complete the conversion. Two rate models for gas-solid reaction were applied to describe the effect of char conversion on reaction rate. The shrinking core model for reaction-controlled regime was found to be the best for predicting the rate of char gasification in $\mathrm{CO}_{2}$ and $\mathrm{O}_{2}$ atmosphere. The experimental data for steam gasification of the char were fitted best by the first-order kinetics. The kinetic parameters estimated from the experimental data are in accordance with the literature for lignocellulosic char gasification and are the first published for sewage sludge char gasification.
\end{abstract}

Keywords Gasification - Sewage sludge char .

Kinetic modelling

\author{
List of symbols \\ $\alpha \quad$ Conversion (-) \\ $C$ Concentration $\left(\mathrm{mol} \mathrm{dm}^{-3}\right)$ \\ $d_{0} \quad$ Initial sample particle diameter (m) \\ $E \quad$ Activation energy $\left(\mathrm{kJ} \mathrm{mol}^{-1}\right)$
}

L. Nowicki · A. Antecka (囚) · T. Bedyk · P. Stolarek ·

S. Ledakowicz

Technical University of Lodz, Faculty of Process

and Environmental Engineering, Wolczanska 213,

90-924 Lodz, Poland

e-mail: amich@wipos.p.lodz.pl
$K \quad$ Surface reaction rate constant $\left(\mathrm{s}^{-1}\right)$

$m(t) \quad$ Sample mass at any time $(\mathrm{g})$

$m_{0} \quad$ Initial mass $(\mathrm{g})$

$m_{\mathrm{k}} \quad$ Final mass $(\mathrm{g})$

$n \quad$ Reaction order (-)

$\mathrm{R} \quad$ Universal gas constant $\left(\mathrm{kJ} \mathrm{mol}^{-1} \mathrm{~K}^{-1}\right)$

$r_{\mathrm{s}} \quad$ Structural term (-)

$t \quad$ Time (s)

$T$ Temperature (K)

$y_{\mathrm{g}} \quad$ Concentration of oxidizing agent (mole frac)

\section{Introduction}

Sewage sludge is regarded as the residue produced by the wastewater treatment process. Currently the most widely available option of sludge utilization in the EU are according to Fytili and Zabaniotou [1] the agriculture utilization and the waste disposal sites. However, there is a wide range of other uses for sludge, which exploit its energy, namely the thermal processes. The thermal and chemical processes of sewage sludge conversion consist of pyrolysis, gasification direct combustion and co-combustion [2]. Pyrolysis as the first chemical step in gasification and combustion plays an important role because its conditions highly affect the yields of char and its reactivity $[3,4]$. The conversion of char occurs at higher temperatures when most of thermal decomposition processes are finished. Thus, in gasification process the primary pyrolysis products, condensable and non-condensable vapours and mainly char undergo secondary reactions with gasification reagent forming additional amounts of synthesis gas. Apart from being used as potential fuel, the product of 
gasification, synthesis gas is a useful raw material for chemical industries.

Char gasification kinetics depends on the gasifying agent used and the operation conditions, such as pressure and temperature [5]. On the other side, type and composition of fuel used for char preparation strongly affect the rate of gasification [6, 7]. Gasification is usually carried out with air, oxygen and steam mixtures. The gasification process is very often performed with steam as the gasifying agent; the advantage of using steam is that this process yields higher amounts of hydrogen [7]. However, nowadays when there is a worldwide discussion about utilization of carbon dioxide, the so-called dry gasification by means of $\mathrm{CO}_{2}$ is also of great importance [8, 9]. Also in some places Integrated Coal Gasification Combined Cycle power plants have been developed to reduce $\mathrm{CO}_{2}$ emissions [6]. The presence of $\mathrm{CO}_{2}$ can improve char conversion and decrease the volume of gasification residue [10].

Gasification of sewage sludge as well as co-gasification with coal as integrated processes involving primary and secondary reactions have been widely investigated during recent years [11-18]. However, the literature on the reaction of sewage sludge char with an oxidizing agent, which is considered as the most important step in the overall processes process, is very scarce, in contrast to the literature concerning the coal and biomass chars gasification reactions.

The information which is acquired with kinetic studies can be usefully applied in different fields, such as the interpretation of reaction mechanisms and catalytic phenomena, molecular behaviour, the optimization and development of new chemical processes as well as reactors modelling and simulation. Therefore, the study of chemical reaction kinetics is of interest to both chemists and chemical engineers using and elaborating reaction rates data on different objectives [19]. Then, the study can be oriented to define the kinetics of each reaction in the pattern.

Char gasification kinetics is of great importance in the design of gasification reactors. This is because gasification is a slower process than the initial pyrolysis [20]. Gasification results in continuous changes in char composition. Hence, the char reactivity tends to vary with degree of conversion or time. Therefore, the first-order kinetics often holds only for a part of the conversion interval.

In general, there are many publications concerning gasification kinetics of chars obtained from different types of coal [6, 21-23] or any types of biomass [4, 24-26]. However, according to our knowledge there are no publications on gasification kinetics of char derived from sewage sludge, except the study of Scott et al. [26], who measured the rate of gasification by $\mathrm{CO}_{2}$ of different chars, including char derived from sewage sludge. They found that this char was the most reactive one, due to the largest amount of inorganic material, components of which catalyse the gasification of carbon by $\mathrm{CO}_{2}$. The reactivity of pyrolyzed sewage sludge in air and carbon dioxide was studied by Inguanzo et al. [27].

In this article, the effect of oxidizing reagent on the kinetics of gasification of char derived from sewage sludge was studied using thermogravimetric analysis and modelling. Gasification rate equations and kinetic parameters for different oxidizing agents $\left(\mathrm{O}_{2}, \mathrm{H}_{2} \mathrm{O}\right.$ and $\left.\mathrm{CO}_{2}\right)$ were obtained. Kinetic analysis is mainly used as a tool for extracting valuable information about the gasification step from a series of measurements with many data points in the form of models with limited number of parameters. We believe that these models can be eventually extrapolated to the industrial applications.

\section{Materials and methods}

Gasification of sewage sludge char was performed in a thermobalance (Netzsch STA 409 PG, Germany). The digested sewage sludge containing about $46 \mathrm{wt} \%$ of ash (on dry mass basis) from Waste Water Treatment Plant in Lodz, Poland was used for char preparation. The results of proximate and ultimate analysis of sewage sludge are presented in Table 1. Proximate analysis of moisture, volatiles, char and ash was performed in preliminary experiment where the samples of sewage sludge were heated to $1000{ }^{\circ} \mathrm{C}$ in the inert gas (argon) and then kept at this temperature in air atmosphere to burn out the char formed during the pyrolysis. The contents of $\mathrm{C}, \mathrm{H}, \mathrm{N}, \mathrm{S}$ and $\mathrm{O}$ elements were determined by an elemental analyser (CE Instruments NA 2500). The results from elemental analysis were used to estimate the heating value of the studied sample.

The char was obtained by devolatilization of sewage sludge in a quartz fixed-bed reactor $(20 \mathrm{~mm}$ internal diameter) heated by an electric furnace in at $1000{ }^{\circ} \mathrm{C}$ under an argon stream. The sample of dried and ground sewage sludge was heated at the constant heating rate of $100{ }^{\circ} \mathrm{C} / \mathrm{h}$ and then held in final conditions $\left(1000{ }^{\circ} \mathrm{C}\right)$ for about $120 \mathrm{~min}$. Then the char was cooled under a flow of argon to room temperature, and sieved. The fraction of the char particle diameter less than $70 \mu \mathrm{m}$ was used for gasification tests.

Table 1 Proximate and ultimate analyses of sewage sludge samples

\begin{tabular}{|c|c|c|c|c|c|c|c|c|c|}
\hline \multicolumn{4}{|c|}{ Proximate analysis/wt $\%$} & \multicolumn{5}{|c|}{ Ultimate analysis/wt $\%$} & \multirow{2}{*}{$\begin{array}{l}\mathrm{HV} / \\
\mathrm{MJ} \mathrm{kg}^{-1}\end{array}$} \\
\hline Moisture & Volatiles & Char & Ash & $\mathrm{N}$ & $\mathrm{C}$ & $\mathrm{H}$ & $\mathrm{S}$ & $\mathrm{O}$ & \\
\hline 5.3 & 44.6 & 7.4 & 42.7 & 2.8 & 26.0 & 3.5 & 1.1 & 23.9 & 10.1 \\
\hline
\end{tabular}


The gasification tests with sewage sludge char were performed under atmospheric pressure. The thermobalance was equipped with the water vapour furnace enabling a measurement in the atmosphere containing a controlled amount of steam. Except water vapour, mixtures of oxygen or carbon dioxide diluted with argon were used for gasification. The total flow rate of gas introduced into the thermobalance during the experiments was $50 \mathrm{~cm}^{3} / \mathrm{min}$ (in the case of reactive gas containing steam, the total flow rate was greater than $50 \mathrm{~cm}^{3} / \mathrm{min}$ by a stream of water vapour produced in the steam generator). The char sample was placed in an alumina crucible $5 \mathrm{~mm}$ diameter and $3 \mathrm{~mm}$ height. The mass of sample used was about $20 \mathrm{mg}$. The rates of char gasification were measured under isothermal conditions at different temperatures depending on the gasifying agent used.

To determine the temperature range where different reactive gases are active in the gasification reaction, preliminary experiments were performed, additionally under dynamic conditions. During these experiments the char samples were heated at the constant heating rate of $10{ }^{\circ} \mathrm{C} / \mathrm{min}$ from room temperature to $1000{ }^{\circ} \mathrm{C}$. Three different oxidizing atmospheres were applied: 10 vol.\% $\mathrm{O}_{2} / 90 \% \mathrm{Ar} ; 50 \% \mathrm{CO}_{2} / 50 \% \mathrm{Ar}$ and $16 \% \mathrm{H}_{2} \mathrm{O} / 84 \% \mathrm{Ar}$.

\section{Results and discussion}

Figure 1 shows a comparison of TG (Fig. 1a) and DTG (Fig. 1b) profiles for the char gasification with different oxidizing agents under non-isothermal conditions. The gas containing $10 \%$ of oxygen reacts with char at relatively low temperatures. In this case the reaction starts at about $400{ }^{\circ} \mathrm{C}$ and reaches the maximum rate at $540{ }^{\circ} \mathrm{C}$. The gases containing $50 \%$ of $\mathrm{CO}_{2}$ and $16 \%$ of $\mathrm{H}_{2} \mathrm{O}$ in argon react with char only above 700 and $750{ }^{\circ} \mathrm{C}$, respectively. The maximum rate with carbon dioxide was observed at $806{ }^{\circ} \mathrm{C}$, whereas for steam it was shifted to $934{ }^{\circ} \mathrm{C}$. It is worth to notice that the maximum reaction rate measured at dynamic conditions was similar for all oxidizing reagents used.
As can be seen in the Fig. 1, there are differences in total mass loss depending on the oxidizing reagent used. At the final temperature of $1000{ }^{\circ} \mathrm{C}$ the total mass loss in the case of oxygen was $18 \%$ of the initial mass, whilst in the case of $\mathrm{CO}_{2}$ and steam it was about $21 \%$. The higher mass loss for $\mathrm{CO}_{2}$ and $\mathrm{H}_{2} \mathrm{O}$ may be explained by the interaction of these gases with some components of a mineral layer (ash) of the char, which was observed during our studies of catalytic effects of ash in pyrolysis and gasification processes [28]. This interaction can be also seen, before the chemical reaction starts (see Fig. 1), as a small increase of the sample mass, which was probably caused by adsorption of gaseous reagents on the solid surface. It is generally accepted that the adsorption of the gas component is the first step in the mechanism of char gasification process [4].

The mass loss data recorded by thermobalance were then recalculated to express conversion as a function of time. The char conversion $\alpha$ in the gasification reaction was defined as:

$\alpha(t)=\frac{\Delta m_{\mathrm{k}}-\Delta m(t)}{\Delta m_{\mathrm{k}}}$

where: $\quad \Delta m_{\mathrm{k}}=m_{0}-m_{\mathrm{k}}, \quad \Delta m(t)=m_{0}-m(t), \quad$ and $\quad m_{0}$ denotes the initial mass of char, $m(t)$ the sample mass at any time $t$ and $m_{\mathrm{k}}$ the mass of ash. The sewage sludge char conversion versus time data for different oxidizing atmospheres: $\mathrm{O}_{2}, \mathrm{H}_{2} \mathrm{O}$ and $\mathrm{CO}_{2}$ at different temperatures are shown in Fig. 2a-c, respectively.

To determine the effect of oxidizing agent concentration on the gasification rate, experiments at fixed temperature (500, 800 and $850{ }^{\circ} \mathrm{C}$ ) for each reagent $\left(\mathrm{O}_{2}, \mathrm{H}_{2} \mathrm{O}\right.$ and $\left.\mathrm{CO}_{2}\right)$, respectively, were performed. These data are presented in Fig. 2d-f.

Assuming that gasification is a one-step reaction, the conversion in an isothermal batch reactor can be expressed by the following equation:

$\frac{\mathrm{d} \alpha}{\mathrm{dt}}=k\left(y_{\mathrm{g}}, T\right) r_{\mathrm{s}}(\alpha)$

where $k$ is the reaction rate term including the effect of gasifying agent concentration $\left(y_{\mathrm{g}}\right)$ and the effect of
Fig. 1 TG (a) and DTG

(b) curves for thermochemical decomposition of sewage sludge char under different atmospheres
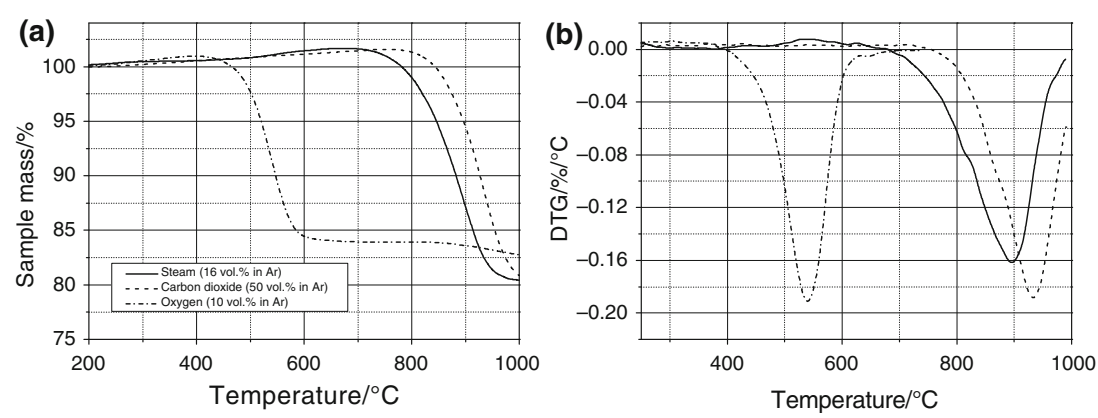
Fig. 2 Experimental conversion for thermochemical decomposition of pyrolysis char under different temperatures and atmospheres
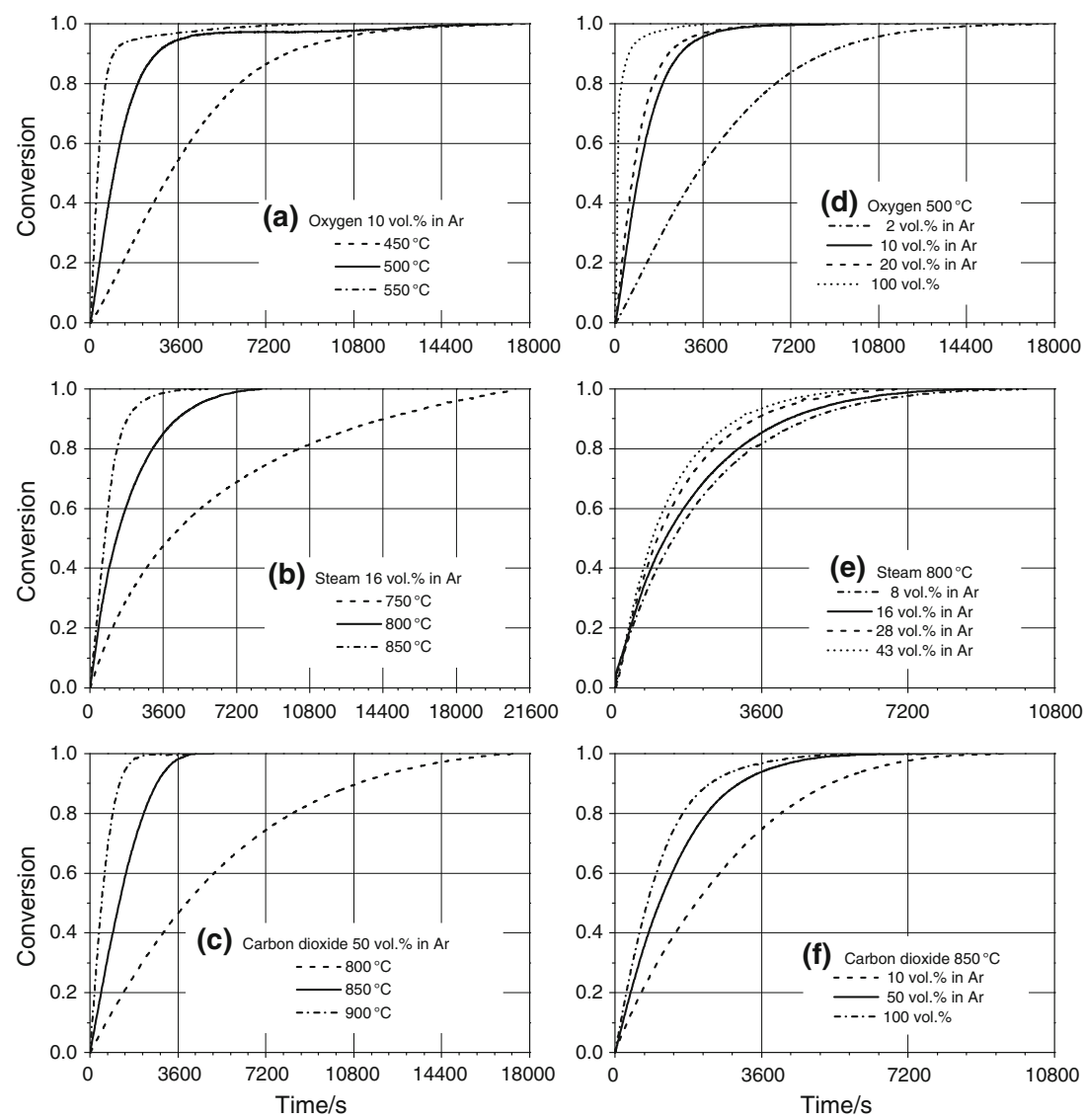

temperature (T), and $r_{\mathrm{s}}$ is a structural term assumed to describe the changes in available internal surface and structural properties of the char as the reaction proceeds. The first term in Eq. 2 can be described by:

$k\left(y_{\mathrm{g}}, T\right)=k_{\mathrm{o}} e^{-E / R T} y_{\mathrm{g}}^{n}$

where $k_{\mathrm{o}}$ and $E$ are pre-exponential factor and activation energy, respectively, and $n$ is the reaction order in respect to the concentration of gasifying agent.

Many different functions can be used to describe changes in the physical properties of the solid comprised in the $r_{\mathrm{s}}$ term. In this study, the two simple models are applied. In modelling of char gasification reactions it was assumed that the pseudo-homogeneous kinetic equation could be applied [29]. Thus, the simple pseudo-homogeneous volume-reaction model for the first-order reaction with respect to solid substrate was often used to evaluate the overall reaction rate of char gasification. For the first-order kinetics the following equation can be used

$\frac{\mathrm{d} \alpha}{\mathrm{dt}}=k_{\mathrm{v}}(1-\alpha)$

or in the integrated form

$-\ln (1-\alpha)=k_{v} t$ where $k_{\mathrm{v}}$ is the reaction rate constant equivalent to $k$ function defined by Eq. 3. For this type of kinetics, the plot of $-\ln (1-\alpha)$ versus time $t$ should give a straight line whose slope is $k_{\mathrm{v}}$.

The shrinking core model usually used for incineration assumes that the reaction takes place on the surface of a spherical solid particle [30]. In the chemical reaction regime with assumption of the spherical shape of particles, the following equation can be applied:

$\Phi(\alpha)=1-(1-\alpha)^{1 / 3}=k_{\mathrm{s}} t$

where $k_{\mathrm{s}}$ means the apparent rate constant for shrinking core model, which depends on temperature and gaseous reagent concentration.

The reaction rate constants $k_{\mathrm{v}}$ and $k_{\mathrm{s}}$ can be calculated using the experimental results shown in Fig. 3a, c, e, and b, $\mathrm{d}$, f from the slopes of plots representing Eqs. 5 and 6, respectively. These figures show the application of the firstorder and shrinking core models to the experimental results obtained for the gasification of sewage sludge char at different temperatures and for different oxidizing agents.

The relationship between the left-hand side of Eqs. 5 or 6 versus time should be a straight line to prove validity of the model. Figure 3 shows the application of these two 
Fig. 3 Plots of the linearized volumetric first-order (left side plots) and shrinking core (right side plots) model equations for sewage sludge char gasification under different atmospheres. Effect of temperature
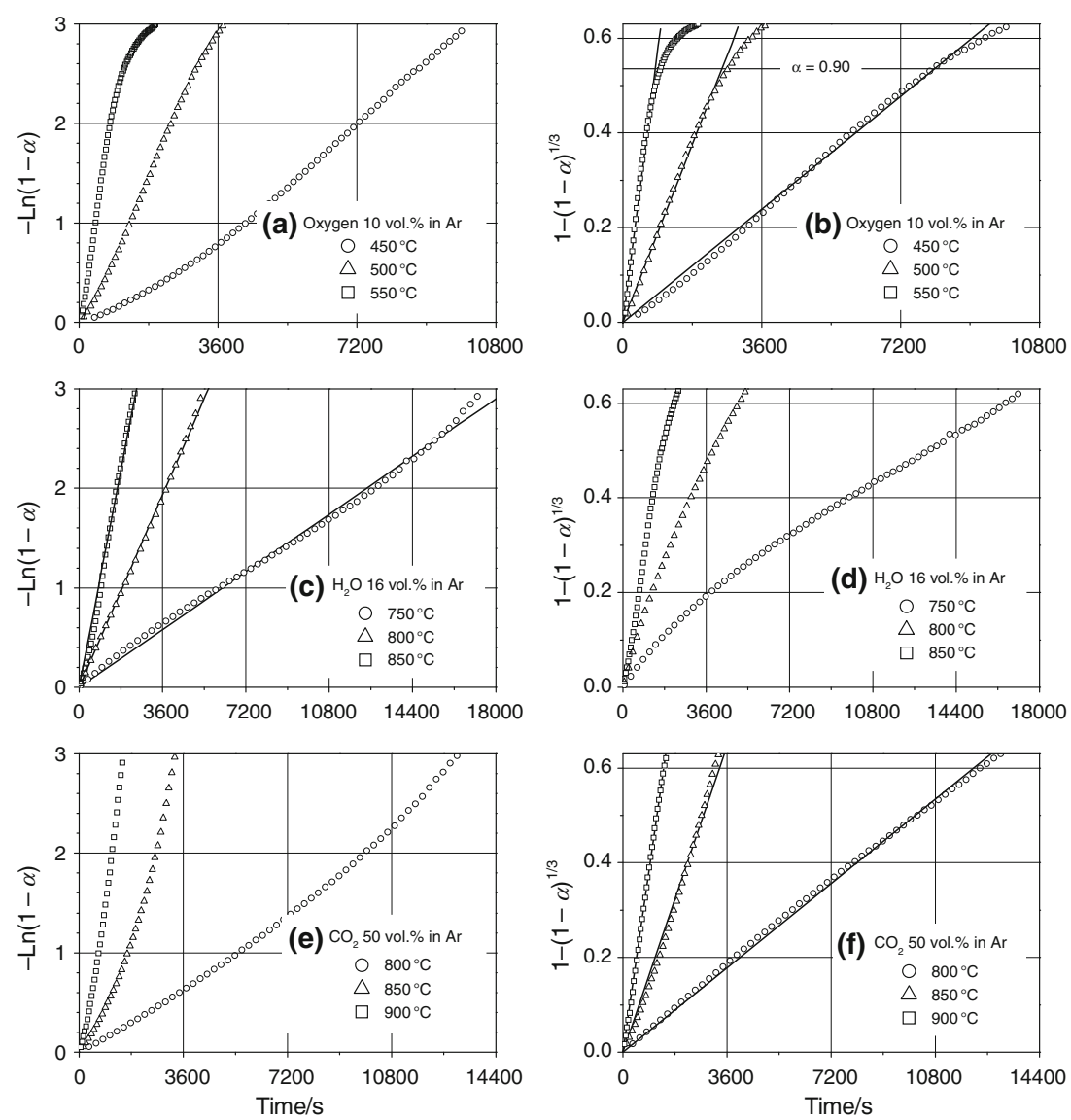

equations to the experimental results obtained for the gasification of char at different temperatures and oxidizing atmospheres. A range of conversions varied from 0.05 to 0.95 is presented on the plots. The analysis of data presented in Fig. 3 leads to the conclusion that the first-order reaction model can be only applied for the steam gasification in the whole range of conversion (0.05-0.95). In the case of oxygen and carbon dioxide the shrinking core model predicts the experimental data much better; however, for the reactive gas containing $10 \mathrm{vol} . \%$ oxygen, the model is valid only for the char conversion below $90 \%$. The validity of the first-order kinetics may suggest that steam gasification of char proceeds according to different mechanism than that for gasification with carbon dioxide and oxygen. As it was mentioned above, the shrinking core model (as well as the first-order model) does not predict the experimental data for oxygen over 85-93\% of conversion. It might be possible that diffusion limitations can play an important role in this conversion region. The sewage sludge char is a porous material with a complex structure (distribution of pores within the particle) [26], which makes it difficult to reach the solid surface by reacting gas in the micro-porous region where the char is only available at the end of the reaction. As can be seen from Fig. 3b, the shrinking core model in the regime of chemical kinetic control reaction can be used only up to certain maximum value of conversion which decreases with increasing temperature (from about $93 \%$ at $450{ }^{\circ} \mathrm{C}$ to about $85 \%$ at $550{ }^{\circ} \mathrm{C}$ ). This finding shows that the effect of intra-particle mass transfer on the rate of reaction is more pronounced at higher temperatures as it could be expected. The diffusion limitation is not important in the case of carbon dioxide, although the same model was proved to be applicable. However, at $800-950{ }^{\circ} \mathrm{C}$, where the $\mathrm{CO}_{2}$ gasification was studied, the reaction was much slower compared to the other gasifying agents (see Fig. 6), so the dry gasification by $\mathrm{CO}_{2}$ was almost certainly limited by the chemical reaction kinetics.

The values of the reaction rate constants determined from the slope of straight lines drawn for the better-fitting models are given in Table 2. Upon correlating these values of rate constants with the temperature (Table 2) according to Arrhenius law (Fig. 4), the activation energy $(E)$ and the pre-exponential factor $\left(k_{\mathrm{o}}\right)$ were obtained.

Table 3 shows the values of parameters $k_{\mathrm{o}}$ and $E$, obtained for three different gasifying reagents. The values of pre-exponential factors and activation energy are in the expected range determined for different biomass char 
Table 2 Kinetic parameters for char gasification with different oxidizing reagents

\begin{tabular}{llrr}
\hline $\begin{array}{l}\text { Reactive } \\
\text { atmosphere }\end{array}$ & $\begin{array}{l}\text { Temperature } / \\
{ }^{\circ} \mathrm{C}\end{array}$ & $k_{\mathrm{v}} / \mathrm{s}^{-1}$ & \multicolumn{1}{c}{$k_{\mathrm{s}} / \mathrm{s}^{-1}$} \\
\hline $10 \mathrm{vol} \% \mathrm{O}_{2} /$ & 450 & & $7.044 \times 10^{-5}$ \\
$90 \% \mathrm{Ar}$ & 500 & & $2.221 \times 10^{-4}$ \\
& 550 & & $7.0611 \times 10^{-4}$ \\
$50 \mathrm{vol} \% \mathrm{CO}_{2} /$ & 800 & & $4.284 \times 10^{-5}$ \\
$50 \% \mathrm{Ar}$ & 850 & & $1.965 \times 10^{-4}$ \\
& 900 & $1.619 \times 10^{-4}$ & \\
$16 \mathrm{vol} \% \mathrm{H}_{2} \mathrm{O} /$ & 750 & $5.482 \times 10^{-4}$ & \\
$84 \% \mathrm{Ar}$ & 800 & $1.210 \times 10^{-3}$ & \\
& 950 & & \\
\hline
\end{tabular}

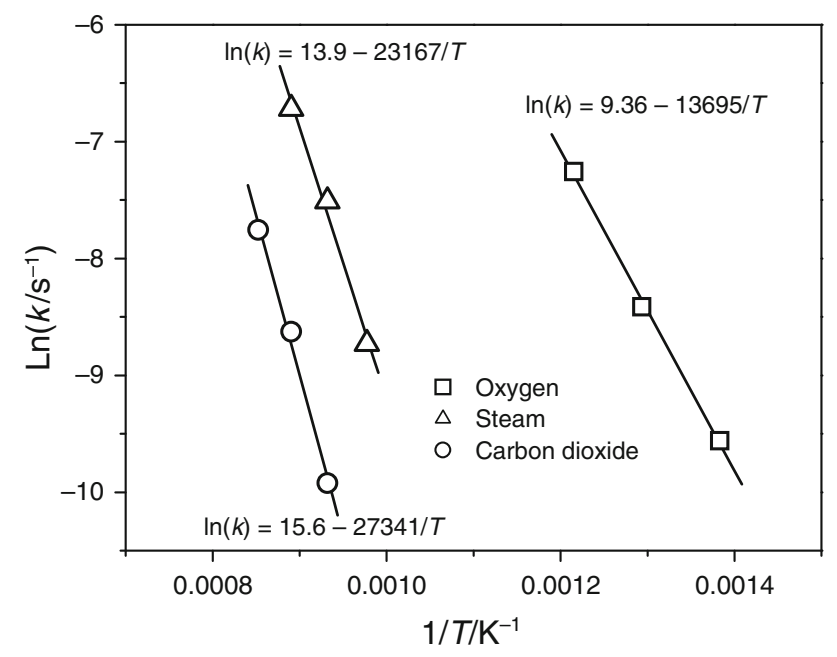

Fig. 4 Arrhenius plots for sewage sludge char gasification with different oxidizers

gasification reactions (e.g. Di Blasi [4], Fermoso et al. [7], Klose and Woelki [25]). However, the activation energy for carbon dioxide $(223 \mathrm{~kJ} / \mathrm{mol})$ is slightly lower than the value of $260 \mathrm{~kJ} / \mathrm{mol}$ given by Scott et al. [26] for char derived from sewage sludge containing similar amount of ash.

Analysis of results shown in Fig. 2d-f concerning the effect of concentration of oxidizing reagents on the conversion leads to the conclusion that the same kinetic models, as discussed above, can be also applied for the whole range of concentration of gaseous reagent. Figure 5 shows the application of the kinetic models discussed earlier to experimental results obtained during gasification of sewage sludge char under reactive gas atmospheres containing different amounts of the oxidizing agent.

The shrinking core model was found again to be the most suitable one for all studied concentrations of oxygen
Table 3 Comparison of kinetic parameters of char during gasification with different oxidizers

\begin{tabular}{llll}
\hline Oxidizing reagent & $k_{\mathrm{os}} / \mathrm{s}^{-1}$ or $k_{\mathrm{ov}} / \mathrm{s}^{-1}$ & $E / \mathrm{kJ} \mathrm{mol}^{-1}$ & $n$ \\
\hline Oxygen & $1.16 \times 10^{4}$ & 114 & 0.88 \\
Carbon dioxide & $5.96 \times 10^{6}$ & 227 & 0.39 \\
Steam & $1.09 \times 10^{6}$ & 193 & 0.30 \\
\hline
\end{tabular}

and carbon dioxide. As an example, the data for oxygen are shown in Fig. 5a. It is worth to notice that this model is also valid for $100 \% \mathrm{O}_{2}$; however, in this case the upper limit of its applicability is only to about $85 \%$ of conversion. Figure $5 \mathrm{~b}$ confirms that the first-order reaction model gives a good prediction of experimental data for steam gasification process in the studied range of $\mathrm{H}_{2} \mathrm{O}$ concentration.

The gasification and combustion of char are the complex reactions taking place according to several steps as summarized in the article by Di Blasi [4]. In general, the gasification or combustion reaction is initiated by reversible adsorption of gasifying species on active carbon site followed by surface reaction and gaseous products formation. Taking into account the detailed mechanism of gasification process, the Langmuir-Hinshelwood type of kinetic equation describing effect of gasifying reagent concentration on the overall reaction rate can be derived. In thermogravimetric measurements where the product concentrations are low enough and/or the inhibiting effect exerted by the product gases can be ignored, the more complicated Langmuir-Hinshelwood equation is often approximated by simple form represented by Eq. 3 [4].

The reaction rate constants determined for various concentrations of gasifying reagent were presented in double-log plot in Fig. 6. These results were used to determine parameter $n$ in Eq. 3 which is a formal reaction order with respect to oxidizing agent. The values of parameter $n$ for different gases are given in Table 3.

An examination of the results of the biomass gasification kinetics evaluation shows that the exponent of the gaseous reactant pressure is around 0.4-1 [4]. The higher value of reaction order for oxygen $n=0.88$ and the lower value of reaction order with respect to $\mathrm{CO}_{2} n=0.39$ are in accordance with the literature data. However, the value 0.3 for steam gasification is lower, we have to notice that this value was obtained for sewage sludge, which is not the same as lignocellulosic chars analysed by Di Blasi [4]. It is known that differences in char reactivity and values of kinetic parameters (activation energy and reaction orders) are caused by the biomass property, especially by the ash content due to its catalytic properties. The lower value of the parameter $n$ reflects the strong inhibiting effects of steam and carbon dioxide adsorption on the gasification rate. 
Fig. 5 Plots of the linearized model equations for gasification of sewage sludge char by oxygen at $500{ }^{\circ} \mathrm{C}$ and steam at $850{ }^{\circ} \mathrm{C}$. Effect of gasifying agent concentration
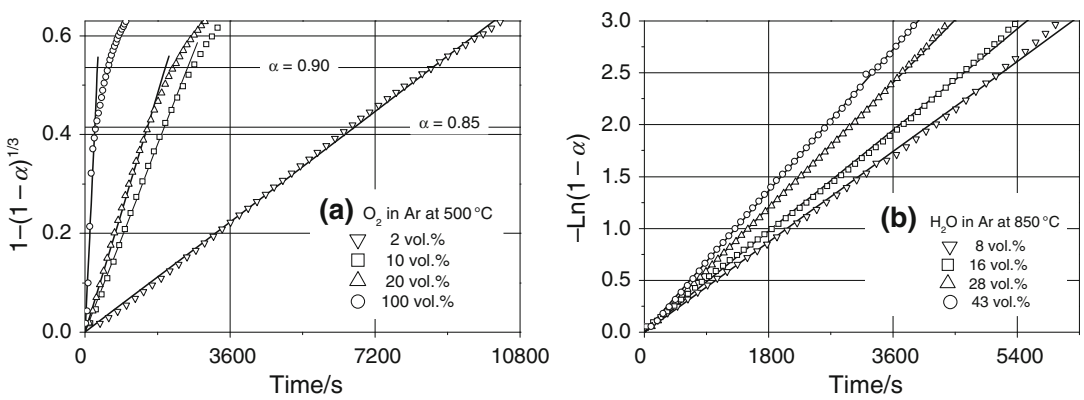

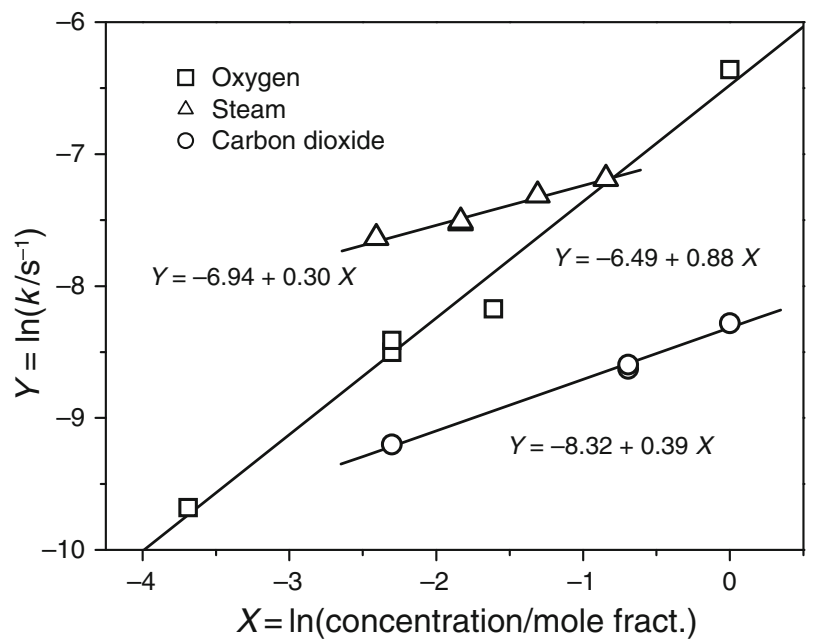

Fig. 6 The effect of oxidizers concentration on reaction rate constant

\section{Conclusions}

Char samples obtained by pyrolysis of municipal sewage sludge were gasified in a thermobalance at atmospheric pressure with oxygen, carbon dioxide or steam to study their reactivity at different temperatures and oxidizing agent concentrations. The thermogravimetric experiments performed in a dynamic mode with constant heating rate showed that oxygen reacts with char at relatively low temperatures. In this case the reaction starts at about $400{ }^{\circ} \mathrm{C}$, whereas carbon dioxide and water vapour react with char only at above $700-750{ }^{\circ} \mathrm{C}$.

To understand the behaviour of pyrolysis char during gasification, several models have been used with different degrees of complexity. In this study, the most common and simpler rate models for gas-solid reaction (volumetric and shrinking core models) have been applied to describe conversion of char during gasification processes. The shrinking core model for reaction-controlled regime was found to be the best for predicting the rate of char gasification up to $90 \%$ conversion in $\mathrm{CO}_{2}$ and in $\mathrm{O}_{2}$ atmosphere. The experimental data for steam gasification of the char were fitted best by the first-order kinetics.
The activation energies and pre-exponential factors were calculated for char gasification with different oxidizing agents using the most suitable models. In addition, the reaction orders in respect to the concentration of each oxidizing agent were determined. These values as well as the activation energies obtained in this study are in the range of values reported in the literature for coal and biomass char gasification processes.

Acknowledgements This study was performed in the frames of project: REduction MOdification \& VALorisation of Sludge Contract nr: FP6-018525, European Union Research, Sixth framework Programme, Priority 1.1.6.3: Global change and ecosystems.

Open Access This article is distributed under the terms of the Creative Commons Attribution Noncommercial License which permits any noncommercial use, distribution, and reproduction in any medium, provided the original author(s) and source are credited.

\section{References}

1. Fytili D, Zabaniotou A. Utilization of sewage sludge in EU application of old and new methods - A review. Renew Sustain Energy Rev. 2008;12:116-40.

2. Werther J, Ogada T. Sewage sludge combustion. Progr Energy Comb Sci. 1999;25:55-116.

3. Cetin E, Moghtaderi B, Gupta R, Wall TF. Influence of pyrolysis conditions on the structure and gasification reactivity of biomass chars. Fuel. 2004;83:2139-50.

4. Di Blasi C. Combustion and gasification rates of lignocellulosic chars. Progr Energy Comb Sci. 2009;35:121-40.

5. Molina A, Mondragón F. Reactivity of coal gasification with steam and $\mathrm{CO}_{2}$. Fuel. 1998;77:1831-9.

6. Kajitani S, Suzuki N, Ashizawa M, Hara S. $\mathrm{CO}_{2}$ gasification rate analysis of coal char in entrained flow coal gasifier. Fuel. 2006;85:163-9.

7. Fermoso J, Arias B, Pevida C, Plaza MG, Rubiera F, Pis JJ. Kinetic models comparison for steam gasification of different nature fuel chars. J Therm Anal Calorim. 2008;91:779-86.

8. Strezov V, Moghtaderi B, Lucas JA. Thermal study of decomposition of selected biomass samples. J Therm Anal Calorim. 2003;72:1041-8.

9. Cormos CC, Starr F, Tzimas E, Peteves S. Innovative concepts for hydrogen production processes based on coal gasification with $\mathrm{CO}_{2}$ capture. Int J Hydrogen Energy. 2008;33:1286-94.

10. Butterman $\mathrm{HC}$, Castaldi MJ. Influence of $\mathrm{CO}_{2}$ injection on biomass gasification. Ind Eng Chem Res. 2007;46:8875-86. 
11. Dogru M, Midilli A, Howarth CR. Gasification of sewage sludge using a throated downdraft gasifier and uncertainty analysis. Fuel Process Technol. 2002;75:55-82.

12. Reed GP, Paterson NP, Zhuo Y, Dugwell DR, Kandiyoti R. Trace element distribution in sewage sludge gasification: source and temperature effects. Energy Fuels. 2005;19:298-304.

13. Manya JJ, Sanchez JL, Gonzalo A, Arauzo J. Air gasification of dried sewage sludge in a fluidized bed: effect of the operating conditions and in-bed use of alumina. Energy Fuels. 2005;19: 629-36.

14. Petersen I, Werther J. Experimental investigation and modeling of gasification of sewage sludge in the circulating fluidized bed. Chem Eng Process. 2005;44:717-36.

15. Petersen I, Werther J. Three-dimensional modeling of a circulating fluidized bed gasifier for sewage sludge. Chem Eng Sci. 2005;60:4469-84.

16. Pinto F, Lopes H, Andre RN, Dias M, Gulyurtlu I, Cabrita I. Effect of experimental conditions on gas quality and solids produced by sewage sludge cogasification. 1. Sewage sludge mixed with coal. Energy Fuels. 2007;21:2137-45.

17. Aznar M, Manyà JJ, García G. Influence of freeboard temperature, fluidization velocity, and particle size on tar production and composition during the air gasification of sewage sludge. Energy Fuels. 2008;22:2840-50.

18. Groß B, Eder C, Grziwa P. Energy recovery from sewage sludge by means of fluidized bed gasification. Waste Manag Res. 2008;28:1819-26.

19. Santacesaria E. Fundamental chemical kinetics: the first step to reaction modelling and reaction engineering. Catal Today. 1999; 52:113-23.
20. Liliedahl T, Sjoestroem K. Modelling of char-gas reaction kinetics. Fuel. 1997;76(1):29-37.

21. Johnson JL. Kinetics of coal gasification. New York: Krieger Publishing Company; 1979.

22. Ozbas KE, Koek MV, Hicyilmaz C. Comparative kinetic analysis of raw and cleaned coals. J Therm Anal Calorim. 2002;69:541-9.

23. Koek MV. Temperature-controlled combustion and kinetics of different rank coal samples. J Therm Anal Calorim. 2005;79:175-80.

24. Henrich E, Buerkle S, Meza-Renken ZI, Rumpel S. Combustion and gasification kinetics of pyrolysis chars from waste and biomass. J Anal Appl Pyrolysis. 1999;49:221-41.

25. Klose W, Woelki M. On the intrinsic rate of biomass char gasification with carbon dioxide and steam. Fuel. 2005;84:885-92.

26. Scott SA, Davidson JF, Dennis JS, Fennell PS, Hayhurst AN. The rate of gasification by $\mathrm{CO}_{2}$ of chars from waste. Proc Combust Inst. 2005;30:2151-9.

27. Inguanzo M, Menendez JA, Fuente E, Pis JJ. Reactivity of pyrolyzed sludge in air and $\mathrm{CO}_{2}$. J Anal Appl Pyrolysis. 2001; 58-59:943-54.

28. Bedyk T, Nowicki L, Stolarek P, Ledakowicz S. Effect of $\mathrm{CaO}$ and dolomite additive in the thermal decomposition of sewage sludge in an inert atmosphere. J Residuals Sci Technol. 2009; 6(1):3-10.

29. Baker RR. Kinetic parameters from the non-isothermal decomposition of a multi-component solid. Thermochim Acta. 1978; 23(2):201-12.

30. Szekely J, Ewans JW, Sohn HI. Gas-solid reactions. New York: Academic Press; 1976. 